\title{
XLIX. The rate of recovery of residual charge in electric condensers
}

\author{
Fred. T. Trouton F.R.S. \& Sidney Russ B.Sc.
}

To cite this article: Fred. T. Trouton F.R.S. \& Sidney Russ B.Sc. (1907) XLIX. The rate of recovery of residual charge in electric condensers, Philosophical Magazine Series 6, 13:77, 577-588, DOI: $10.1080 / 14786440709463635$

To link to this article: http://dx.doi.org/10.1080/14786440709463635

曲 Published online: 16 Apr 2009.

Submit your article to this journal $[\pi$

Џ Article views: 2

Q View related articles $\square$

Citing articles: 1 View citing articles $\square$ 
578 Prof. F. T. Trouton and Mr. S. Russ on the Rate of

The conclusions to be drawn from these experiments are the following :-

(1) The beam of Röntgen rays from a focus-tube which yields a magnetic cathode spectrum is heterogeneous.

(2) A metallic sheet shows selective absorption of the different rays.

(3) This selective absorption does not follow the same law in all metals : in certain pairs of metals the absorption is relatively selective.

Jefferson Physical Laboratory,

Harvard University, Cambridge, U.S.A.

XLIX. The Rate of Recovery of Residual Charge in Electric Condensers. By Fred. T. 'T'rotton, F.R.S., and Sidney Russ, B.Se.*

[Plate XV.]

THE analogy between the phenomenon of residual charge in Leyden jars and the recovery from elastic overstrain in solids has often been pointed out. The theoretical investigations of Boltzmann and the experiments of Kohlrausch and Hopkinson have thrown considerable light on the subject.

In view, however, of recent work done by Mr. A. O. Rankine $\dagger$, and subsequently confirmed by Mr. Phillips $\ddagger$, on the recovery of solids from overstrain by a method in which the strain was kept constant while the stress disappears, it seemed desirable to experimentally examine the relations governing the rate at which residual charge makes its appearance in a discharged condenser under conditions analogous to those of their experiments.

The explanation of the phenomenon of residual charge has been referred $\S$ to a heterogeneity in the structure of the dielectric due to its consisting of parts having diverse conducting and dielectric properties, all however subject to simple linear laws. This hypothesis leads to an exponential expression for the rate of recovery of the residual charge. This

* Communicated by the Physical Society : read March 8, 1907.

$\dagger$ Phil. Mrg. [6] vol. viii. 1904, p. 538 .

\pm Phil. Mag. [6] vol. ix. 1905, p. 513.

\$ Maxwell, vol. i. p. 414 . 
Recovery of Residual Charge in Electric Condensers. 579

explanation is on somewhat the same general lines as and leads to analogous results to that which has been advanced in the case of recovery from elastic overstrain, and which is based on the assumption of the material consisting in part of viscous and in part of purely elastic constitutents. This theory of elastic overstrain leads to an exponential expression for the recovery from the strain in terms of the time. Now no such expression fits experimental evidence, but on the other hand the recovery can be well represented by the logarithm of a quantity proportional to the time of recovery. Thus in Rankine's experiments where a constant strain is maintained, the stress while decreasing is given by

$$
\mathrm{S}=\mathrm{S}_{0}(1-\mathrm{K} \log (p t+1)),
$$

where $S$ represents the stress at any moment required to preserve a constant strain in the stretched substance.

Our work was undertaken in the first place to examine whether the exponential law of the recovery of the Residnal Charge was justified by experimental data, and failing this, to attempt to find a law of the above type agreeing with observation.

The examination of the rate of recovery was carried out in two ways.

Where the Residual Charges were great enougb the current as it came out of the recuperating dielectric was simply passed through a sensitive galvanometer and the rate of recovery thus noted.

This method was found quite feasible in the case of a large condenser, the dielectric of which was celluloid, but was unsuited for mica condensers of the ordinary standard type.

For such, a method was devised in which the plates of the condenser were allowed to charge up to a certain difference of potential (due to the Residual Charge coming out of the dielectric) which was measured by an electrometer, and kept at that difference of potential by inserting a variable resistance in parallel with the condenser.

The difficulty of getting a resistance as high as that required, and one which at the same time could be easily adjusted, was surmounted by adopting ionized air as the material of which the resistance was made. The cross section of this resistance was arranged so as to be easily and quickly varied as alteration in the resistance was required. 


\section{Rate of Recovery, or Current at Constant Difference of Potential.}

In these experiments a constant difference of potential was maintained between the two coatings of the condenser, and the rate at which the Residual Charge leaked out under these conditions was found.

It is clear that if a constant deflexion on the scale of the electrometer can be maintained while the Residual Charge is appearing, then a constant difference of potential exists between the coatings of the condenser.

This constant potential-difference was maintained by the use of a variable resistance obtained by connecting the two coatings of the condenser to two parallel plates of tin, on one of which a thin layer of uranium fluoride, for the purpose of producing the necessary ionization of the air between the plates, was uniformly sifted. Owing to the difference of potential between these plates there will be a gradual leak of the residual charge across the air-gap between them, and if the effective area of the uranium surface can be adjusted the value of this current can be controlled as required. The effective area of the air conductor was regulated by a movable shutter which was made to slide in between the two parallel plates, thus curtailing the active area of the uranium fluoride surface and thereby the cross section of our conductor.

The mode of carrying out an experiment was to allow the difference in potential between the plates of the condenser to rise through the development of residual charge, to a certain selected value, and then to prevent further increase by connecting them through the variable ionized air-resistance. To preserve this constancy in potential the shutter must be continuously pushed in so as to diminish the current at the proper rate, namely, that at which the residual charge is developed by the unstraining dielectric.

The position of the shutter at any moment while being pushed in so as to keep the deflexion of the electrometer constant, could be readily found: this is a measure of the current or the rate at which the charge comes out of the condenser when a constant potential-difference is maintained between its coatings.

A "hand" method was first tried for closing the shutter. The apparatus used is indicated in fig. $1 . \mathrm{K}$ a condenser of mica plates was first charged by a series of cells $\mathrm{C}$ for a definite interval of time ( $1 \frac{1}{2}$ mins.), discharged through the key $\mathrm{B}$, and its two coatings were then connected to the elec- 
Recovery of Residual Charge in Electric Condensers. 581 trometer $\mathbf{E}$, one quadrant of which was earthed. $\mathrm{P}$ and $\mathrm{Q}$ are the two parallel plates, the uranium fluoride being spread on the bottom one $Q$. M the movable shutter was initially drawn right back, thus exposing the whole of the uranium fluoride surface.

Fig. 1.

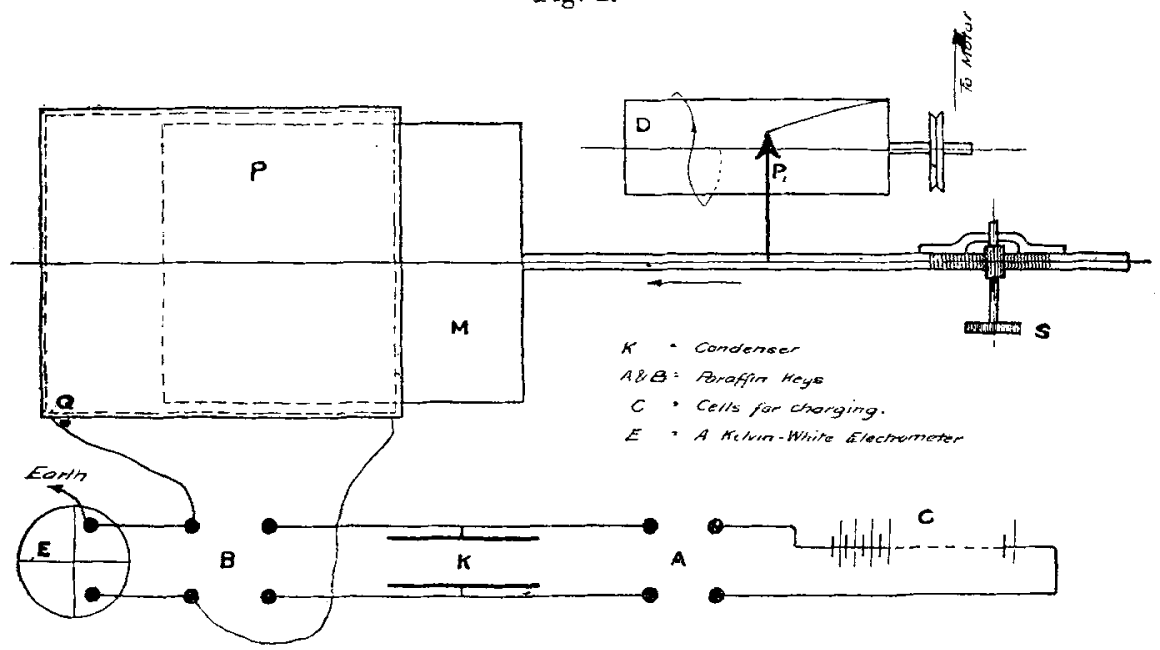

On connecting $\mathrm{K}$ to $\mathrm{E}$ the deflexion increased at first, but owing to the leak introduced the turning point was soon reached; at this instant the shutter $M$ was moved in by means of the wheel $\mathrm{S}$, which engaged in the milling of a brass strip connected to M. The motion of the shutter was recorded by a pointer $\mathrm{P}$ (attached to the brass strip), which traced a path over a blackened surface of paper on a cylindrical drum $D$ which revolved at a known speed by means of a motor, to which it was connected by a system of gearing-down countershafting.

In this way the amount of active area exposed at ench moment was recorded. This was proportional to the conductivity, and consequently to the current developed at each moment by the recovering dielectric.

In controlling the motion of the shutter by hand one is very apt to overshoot the mark, due no doubt to air remaining ionized for a short interval after the shutter has covered the ionizing surface, this making the apparatus slow in responding to any alteration in area. If $S$ is turned too quickly, the leak is being cut too rapidly and the deflexion on the scale increases, so that $\mathbf{S}$ has to he stopped for a short interval in order that the deflexion may return to its former value. On account of this the eurve traced out by $\mathrm{P}$ on the drum was 
582 Prof. F. T. Trouton and Mr. S. Russ on the Rate of

unduly irregular. After many trials made with this apparatus it was decided, for the above reasons, to move the shutter mechanically. The best of the tracings obtained by the previous experiments was utilized for constructing a cam for this purpose. The cam, which was cut out of wood, was made to close the shutter by a uniform rotation about its axis. Fig. 2 illustrates the way in which this was done.

Fig. 2.

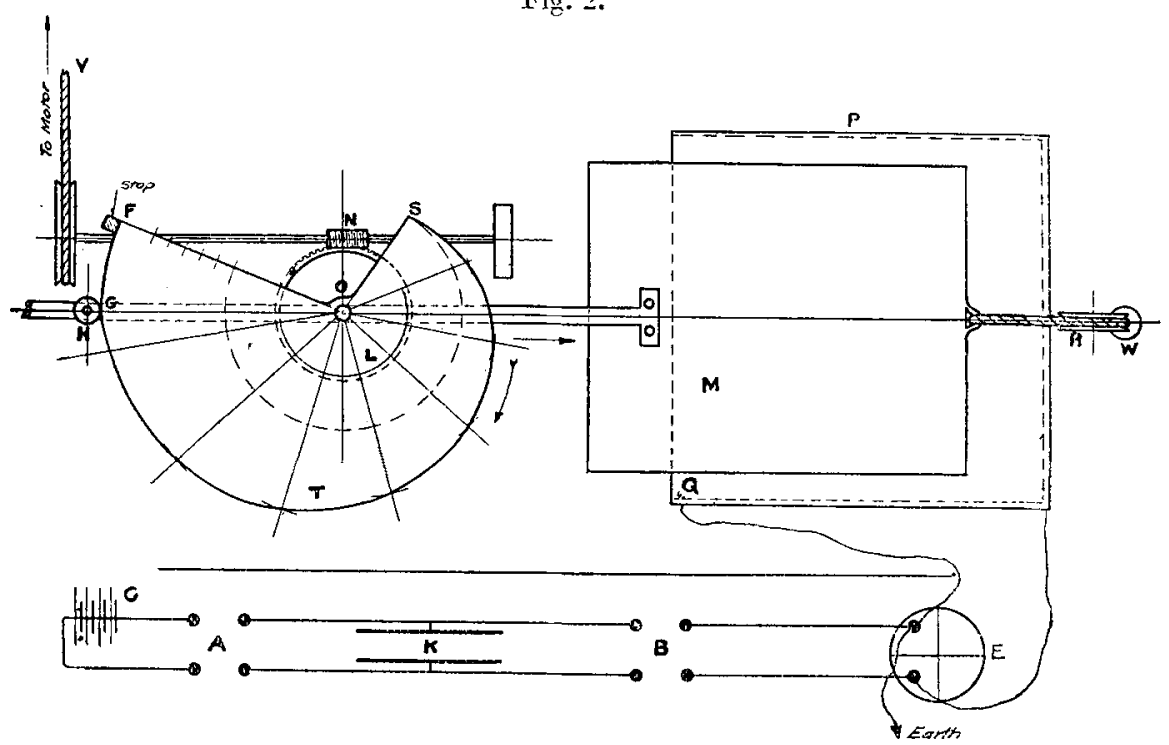

$\mathrm{H}$ is a small brass wheel fixed to a brass strip which passes underneath the cam $\mathrm{T}$ and is joined to the shutter $\mathrm{M}$; a cord fixed to the other end of the shutter passes over a pulley $R$ and carries a weight $W$ which keeps the wheel $\mathrm{H}$ tightly pressed against the cam. As the cam rotates $\mathrm{H}$ is pulled forward and the shutter moves in at a varying speed.

The uniform rotation of the cam was obtained by means of the toothed wheel $\mathrm{L}$, which engaged in an endless worm $\mathrm{N}$ cut in a steel shaft, the other end of which carried a pulleywheel $\mathrm{V}$ which was driven by a small motor highly geared down. The portion FG on the cam entails no forward motion of $\mathrm{H}$, and is to allow the speed of the motor to become constant after starting. The method of carrying out an experiment was as follows :-

The condenser was charged for $1 \frac{1}{2}$ minutes to 20 volts, discharged through the key $\mathrm{B}$, and the coatings then connected to the quadrants and the parallel plates $P, Q$. The 
Recovery of Residual Charge in Electric Condensers. 583 cam was timed so that the point $G$ on it was just opposite $H$ when the coatings of the condenser were connected to $\mathrm{P}, \mathrm{Q}$.

The desired result was that the daflexion of the electrometer remained constant while the shutter was being moved in. How nearly this was attained will be seen from the figs. 3, 4,5 (Pl. XV.), in which the deflexions are plotted against time, the data being given in Tables I., II., III. In each figure the top curve was obtained by allowing the Residual Charge

TABle I.

$\frac{7}{2}$ Partition exposed.

\begin{tabular}{|c|c|c|c|}
\hline \multirow[b]{2}{*}{$\begin{array}{c}\text { Time } \\
\text { in Minutes. }\end{array}$} & \multicolumn{3}{|c|}{ Deflexions of Electrometer. } \\
\hline & $\begin{array}{l}\text { Shutter kept } \\
\text { closed. }\end{array}$ & $\begin{array}{c}\text { Shutter moved in } \\
\text { by cam. }\end{array}$ & $\begin{array}{l}\text { Shutter kept } \\
\text { open. }\end{array}$ \\
\hline 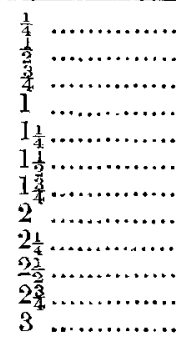 & $\begin{array}{l}15 \cdot 3 \\
17 \cdot 5 \\
18 \cdot 5 \\
19 \\
19 \cdot 3 \\
19 \cdot 5 \\
19 \cdot 6 \\
19 \cdot 5 \\
19 \cdot 4 \\
19 \cdot 3 \\
19 \cdot 2 \\
19 \cdot 1\end{array}$ & $\begin{array}{l}14 \\
14 \cdot 8 \\
15 \\
15 \\
15 \\
15 \\
14 \cdot 9 \\
14 \cdot 8 \\
\uparrow \\
\uparrow\end{array}$ & $\begin{array}{r}13 \cdot 4 \\
13.9 \\
13 \cdot 6 \\
13 \cdot 2 \\
12 \cdot 6 \\
11 \cdot 8 \\
11 \cdot 1 \\
10 \cdot 4 \\
9 \cdot 7 \\
9 \cdot 0 \\
8 \cdot 4 \\
7 \cdot 8\end{array}$ \\
\hline
\end{tabular}

TABLE II.

2 Partitions exposed.

\begin{tabular}{|c|c|c|c|}
\hline \multirow[b]{2}{*}{$\begin{array}{l}\text { Tine } \\
\text { in Minutes. }\end{array}$} & \multicolumn{3}{|c|}{ Deflexions of Electroneter. } \\
\hline & $\begin{array}{c}\text { Shutter kept } \\
\text { closed. }\end{array}$ & $\begin{array}{l}\text { Shutter moved in } \\
\text { by cam. }\end{array}$ & $\begin{array}{c}\text { Shutter kept } \\
\text { open. }\end{array}$ \\
\hline $\begin{array}{l}\frac{1}{4} \\
3 \\
3\end{array}$ & $\begin{array}{l}i 0.5 \\
18.5 \\
18.5 \\
18.85 \\
18.95 \\
18 \cdot 95 \\
18.82 \\
18.65 \\
18 \cdot 50 \\
18.3 \\
18 \cdot 1 \\
18.0\end{array}$ & $\begin{array}{c}15 \cdot 3 \\
15.5 \\
156 \\
156 \\
156 \\
15.65 \\
157 \\
4\end{array}$ & $\begin{array}{l}14 \cdot 9 \\
14 \cdot 3 \\
12: 8 \\
11 \cdot 1 \\
9 \cdot 4 \\
7 \cdot 8 \\
6 \cdot 4 \\
5 \cdot 1 \\
4 \cdot 1 \\
3 \cdot 1 \\
2 \cdot 1 \\
1 \cdot 5\end{array}$ \\
\hline
\end{tabular}


Prof. F. T. Trouton and Mr. S. Russ on the Rate of

TABLE III.

4 Partitions exposed.

\begin{tabular}{|c|c|c|c|}
\hline \multirow[b]{2}{*}{$\begin{array}{l}\text { Time } \\
\text { in Minutes. }\end{array}$} & \multicolumn{3}{|c|}{ Deflexions of Electrometer. } \\
\hline & $\begin{array}{l}\text { Shutter kept } \\
\text { elosed. }\end{array}$ & $\begin{array}{c}\text { Shutter moved in } \\
\text { by cam. }\end{array}$ & $\begin{array}{l}\text { Shutter kept } \\
\text { open. }\end{array}$ \\
\hline 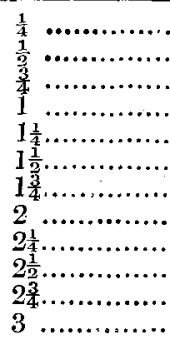 & $\begin{array}{l}14 \cdot 5 \\
15 \cdot 9 \\
16 \cdot 5 \\
16 \cdot 8 \\
16 \cdot 9 \\
16 \cdot 92 \\
16 \cdot 88 \\
16 \cdot 80 \\
16 \cdot 7 \\
16 \cdot 5 \\
16 \cdot 35 \\
16 \cdot 2\end{array}$ & $\begin{array}{c}12 \cdot 1 \\
12 \cdot 1 \\
12 \cdot 05 \\
12 \cdot 1 \\
12 \cdot 3 \\
12 \cdot 3 \\
\uparrow \\
\uparrow\end{array}$ & $\begin{array}{c}10 \cdot 3 \\
8 \cdot 05 \\
6 \cdot 0 \\
4 \cdot 0 \\
2 \cdot 5 \\
1 \cdot 45 \\
\cdot 60 \\
\cdot 01 \\
\uparrow \\
\\
\downarrow\end{array}$ \\
\hline
\end{tabular}

to come out of the condenser in the ordinary unrestrained way, no correction being made for surface leakage. The middle curve was obtained with the cam in action, and the bottom curve with the plate $Q$ fully exposed the whole time, thus showing how the Residual Charge immediately begins to leak across the gap between the two parallel plates $\mathrm{P}, \mathrm{Q}$.

The plate $Q$, upon which the uranium fluoride was spread, was divided into six partitions which could be separately covered with metal sheets, thus varying the surface over which the leak took place.

Fig. 5 was obtained with $\frac{1}{2}$ partition exposed.

Fig. $6 \quad " \quad, \quad 2$ partitions exposed.

Fig. $7 \quad " \quad " 4$ partitions exposed.

From the foregoing curves it was seen that the shape of the cam was approximately correct as it maintained the deflexion of the electrometer constant.

Now since the difference of potential between the coatings of the condenser was constant, the rate the Residual Charge was coming out of the condenser at any moment (and passing across the space between the two parallel plates) was proportional to the area of the bottom plate exposed. This, in turn, was proportional to $\left(L_{t}-O S\right)$, where $L_{t}$ is the length of the radius vector of the cam which at any moment passes through $\mathrm{H}$, and $\mathrm{OS}$ is the length of the radius vector when 
Recovery of Residuail Charge in Electric Condensers. $\quad 585$

the shutter is closed and therefore no current passing across the air-gap.

If, then, we plot the values of $\left(\mathrm{L}_{t}-\mathrm{OS}\right)$ against time, we obtain the rate at which the Residual Charge came out of the condenser under a constant difference of potential.

In all the experiments, however, surface-leakage was present. Its value in terms of the uranium-fluoride leak was always found after the main experiment was finished. Owing to this surface-leakage a certain quantity (which admits of easy calculation) must be added to the value of $\left(\mathrm{L}_{t}-\mathrm{OS}\right)$ in order to give the rate of appearance of Residual Charge.

This has been done, and the corrected ralues of $\left(\mathrm{L}_{t}-\mathrm{OS}\right)$ which represent current have been plotted against time in figs. $6,7,8$, where ordinates represent current and abscissæ time. The data corresponding to these figures will be found in Tables IV., V., and VI.

Table IV.

$\frac{1}{2}$ Partition exposed.

\begin{tabular}{|c|c|c|}
\hline \multirow[b]{2}{*}{1 unit $=7 \cdot 5$ seconds } & \multicolumn{2}{|c|}{ Curent (in arbitrary units). } \\
\hline & Observed. & $\begin{array}{c}\text { Calculated } \\
\text { from equation } \\
\mathrm{C}=\frac{d}{t+b}-a .\end{array}$ \\
\hline 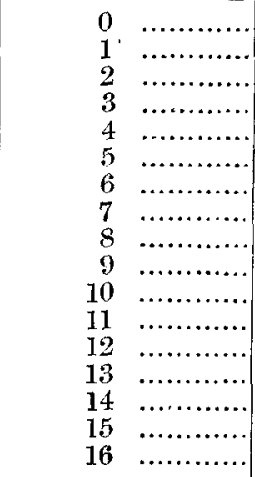 & $\begin{array}{l}6 \cdot 79 \\
5 \cdot 29 \\
4 \cdot 19 \\
3 \cdot 47 \\
3 \cdot 09 \\
2 \cdot 79 \\
2 \cdot 47 \\
2 \cdot 09 \\
1 \cdot 84 \\
1 \cdot 61 \\
1 \cdot 49 \\
1 \cdot 29 \\
1 \cdot 09 \\
\cdot 89 \\
.79 \\
\cdot 65 \\
\cdot 49\end{array}$ & $\begin{array}{l}6 \cdot 79 \\
5 \cdot 35 \\
4 \cdot 36 \\
3 \cdot 64 \\
3 \cdot 10 \\
2 \cdot 66 \\
2 \cdot 31 \\
2 \cdot 05 \\
1 \cdot 78 \\
1 \cdot 57 \\
1 \cdot 40 \\
1 \cdot 23 \\
1 \cdot 10 \\
\cdot 97 \\
\cdot 81 \\
\cdot 77 \\
.68\end{array}$ \\
\hline
\end{tabular}

Values of constants in the above equation:-

$$
a=1 \cdot 01, \quad b=4 \cdot 44, \quad d=34 \cdot 63 .
$$


586 Prof. F. T. Trouton and Mr. S. Russ on the Rate of

TABLE V.-2 Partitions exposed.

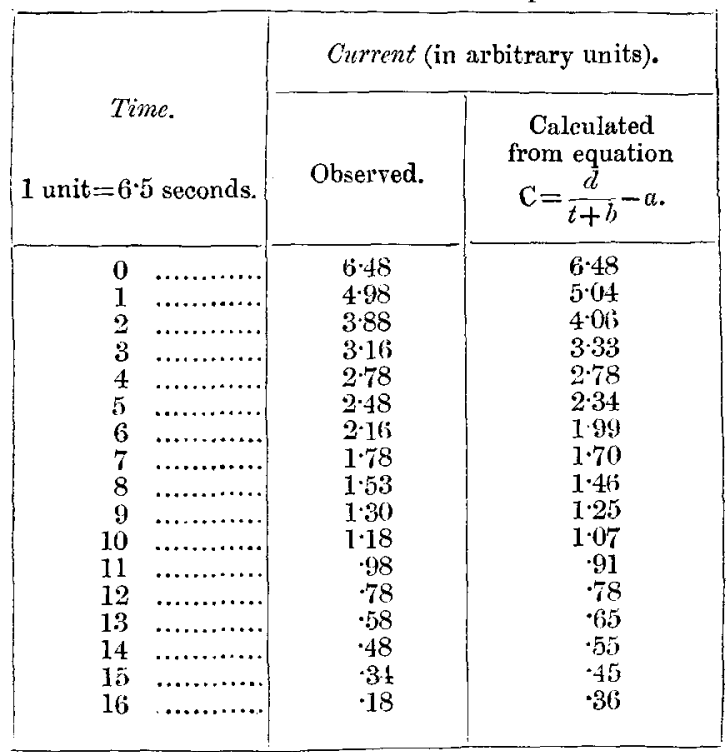

Values of constants in the above equation:-

$$
a=1 \cdot 33, \quad b=4 \cdot 44, \quad d=34 \cdot 68 \text {. }
$$

TABLE VI.-4 Partitions exposed.

\begin{tabular}{|c|c|c|c|}
\hline \multirow{2}{*}{\multicolumn{2}{|c|}{1 unit $=5$ seconds. }} & \multicolumn{2}{|c|}{ Current (in arbitrary units). } \\
\hline & & Observed. & $\begin{array}{c}\text { Calculated } \\
\text { from equation } \\
\mathbf{C}=\frac{\bar{d}}{t+b}-a .\end{array}$ \\
\hline $\begin{array}{r}0 \\
1 \\
2 \\
3 \\
4 \\
5 \\
6 \\
7 \\
8 \\
9 \\
10 \\
11 \\
12 \\
13 \\
14 \\
15 \\
16\end{array}$ & 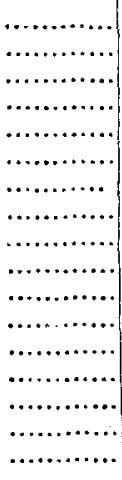 & $\begin{array}{l}6 \cdot 42 \\
4 \cdot 92 \\
3 \cdot 82 \\
3 \cdot 10 \\
2 \cdot 72 \\
2 \cdot 42 \\
2 \cdot 10 \\
1 \cdot 72 \\
1 \cdot 47 \\
1 \cdot 24 \\
1 \cdot 12 \\
\cdot 92 \\
\cdot 72 \\
\cdot 52 \\
\cdot 42 \\
\cdot 28 \\
\cdot 12\end{array}$ & $\begin{array}{c}6 \cdot 42 \\
4 \cdot 98 \\
3 \cdot 99 \\
3 \cdot 27 \\
2 \cdot 72 \\
2 \cdot 29 \\
1 \cdot 94 \\
1 \cdot 68 \\
1 \cdot 41 \\
1 \cdot 20 \\
1 \cdot 03 \\
.86 \\
\cdot 73 \\
\cdot 60 \\
\cdot 44 \\
\cdot 40 \\
.31\end{array}$ \\
\hline
\end{tabular}

Values of constants in the above equation :-

$$
a=1 \cdot 38, \quad b=4 \cdot 44, \quad d=34 \cdot 63 .
$$


Fig. 6 corresponds to the case of $\frac{1}{2}$ partition exposed.

Fig. $7 \quad, \quad, \quad, \quad 2$ partitions exposed.

Fig. $8 \quad$ " $, \quad, 4$ partitions exposed.

The amount of surface-leakage can be seen from Table VII.

TABLE VII.

\begin{tabular}{|c|c|c|}
\hline $\begin{array}{c}\text { Partitions } \\
\text { exposed. }\end{array}$ & $\begin{array}{c}\text { Ratio: } \\
\text { Surface Leakage } \\
\text { Uramium Leakage }\end{array}$ & Percentage. \\
\hline$\frac{1}{2}$ & $\frac{.0137}{175}$ & $7 \cdot 8$ \\
2 & $\frac{.015}{.52}$ & $2 \cdot 9$ \\
4 & $\frac{.0118}{646}$ & 1.8 \\
\hline
\end{tabular}

The corrected values of the current when plotted against time were found not to agree with an equation of the exponential type, with which they should, were the actions going on in an unstraining dielectric in agreement with the theory of heterogeneous structure as given by Maxwell.

An equation of the form

$$
\mathrm{C}=\frac{d}{t+b}-a
$$

was found to fit the experimental curves, figs. $6,7, \& 8$ well. In these figures the continuous lines are obtained from the above equation, and the experimental values appear as circles.

\section{Galvanometer Method.}

The condenser used in these experiments was of about 5 microfarads. It was found to afford a very large residual charge. Celluloid sheets, in conjunction with layers of paper, laid on either side, were employed in its construction. This gave a dielectric of avowedly heterogeneous structure, and therefore might very well be expected to act in accordance with the exponential law; nevertheless it will be seen, from the character of the curves obtained with it, that this is not the case.

The method of experiment was to charge the condenser up to about 20 volts, discharge, and connect with a lowresistance D'Arsonval galvanometer which was practically 


\section{Recovery of Residual Charge in Electric Condensers.}

dead-beat. A sufficient current was then obtained, which was read at frequent intervals until too small to be observed. Two persons were required for this-one to note when the spot of light passed the divisions on the scale, the other to take the time of doing so.

It was always found possible to fit a hyperbola to the observations so obtained. One of the series (Table VIII.) of observations is shown plotted in fig. 9. The curve

$$
\mathrm{C}=\frac{2304 \cdot 4}{t+8 \cdot 94}
$$

was found to suit these observations, and is there shown. The experimental points are seen to tit the curve in a most satisfactory way.

TABLE VIII.

\begin{tabular}{|c|c|c|c|}
\hline $\mathrm{C}$. & $t$. & $\mathrm{c}$. & $t$. \\
\hline 258 & 0 & 25 & 79 \\
208 & 3 & 23 & 87 \\
158 & 7 & 21 & 97 \\
108 & 13 & 18 & 115 \\
78 & 21 & 16 & 134 \\
$\mathbf{5 8}$ & 30 & 14 & 155 \\
48 & 38 & 12 & 184 \\
43 & 43 & 11 & 203 \\
38 & 49 & 10 & 222 \\
33 & 58 & 9 & 251 \\
28 & 69 & & \\
\hline
\end{tabular}

In these experiments, since the condenser was practically short-circuited, there was comparatively speaking no difference in potential between the plates throughout the recovery; so that the dielectric recovered at its maximum or normal rate.

These and the experiments in the first part of the paper are in accordance with the analogy of recovery of elastic solids from overstrain. The quantity of electricity recovered up to any time $t$ is given by an expression of the type

$$
\mathrm{Q}=a \log (t+b),
$$

which is the expression found by Rankine and others to fit the recovery from overstrain in elastic bodies. 
Trootox \& Ress.
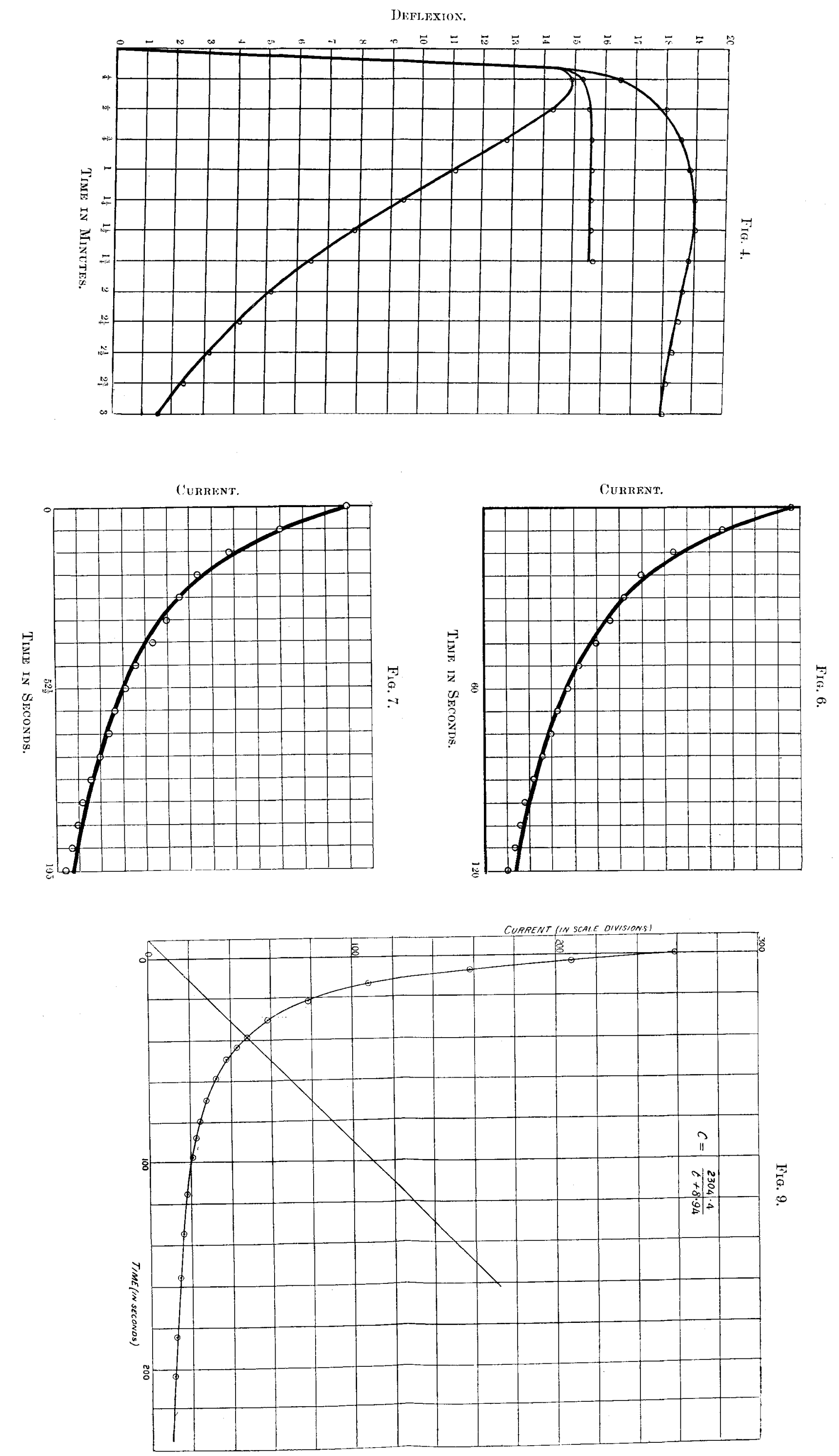

Phil. Mag. Ser. 6, Vol. 13, PI. XV.
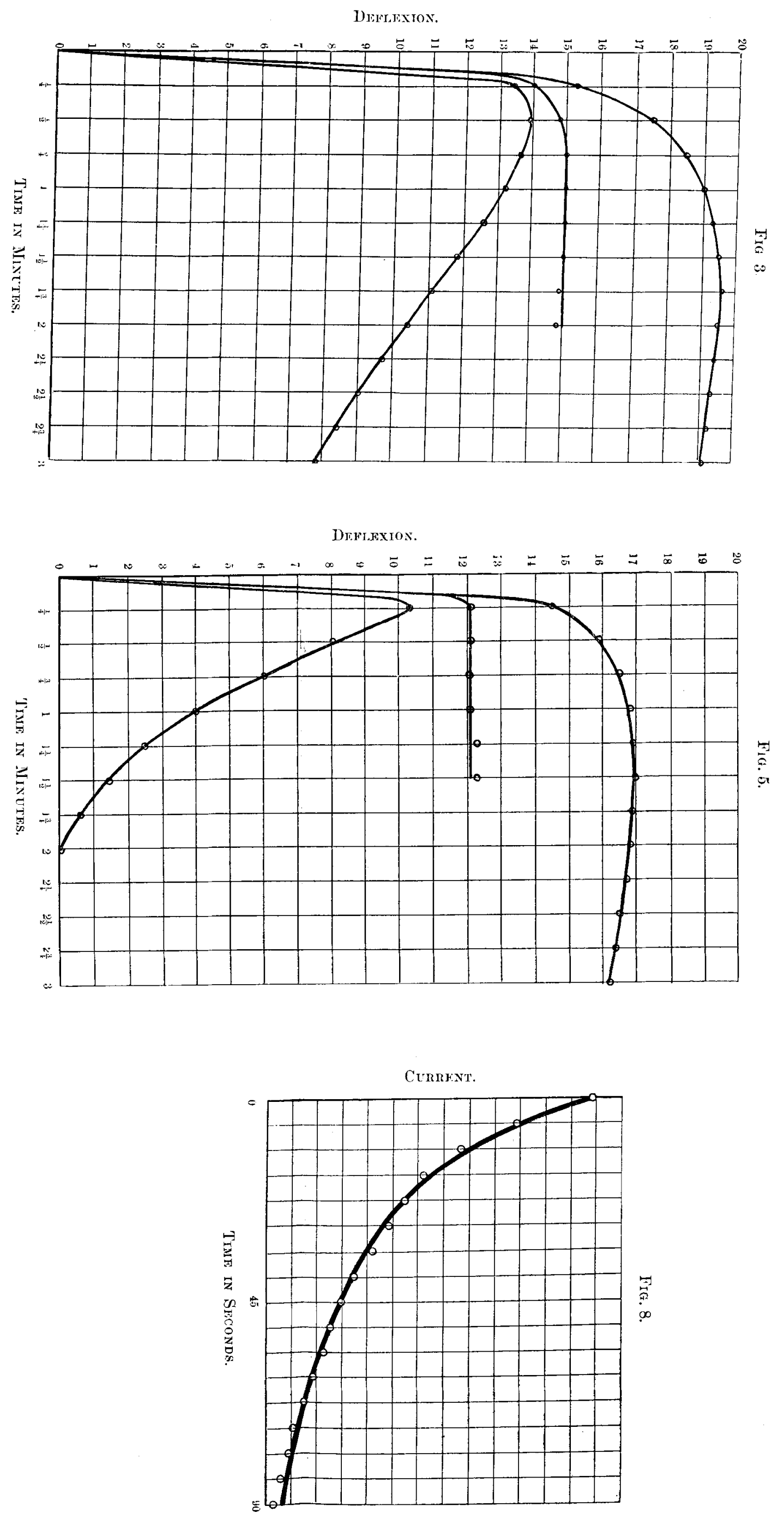